\title{
The Application of Alginate Scaffold in Neural Tissue Engineering
}

\section{Maryam Borhani-Haghighi', ${ }^{1,}$, Shahnaz Razavi ${ }^{3}$, Zahra Khosravizadeh²*}

'Shefa Neuroscience Research Center, Khatam Alanbia Hospital, Tehran, Iran

${ }^{2}$ Department of Anatomy, School of Medicine, Tehran University of Medical Sciences, Tehran, Iran

${ }^{3}$ Department of Anatomical Sciences, School of Medicine, Isfahan University of Medical Sciences, Isfahan, Iran

\section{Received: 14 Jun 2017}

\section{Article Info:}

Revised: 7 May 2017

Accepted: 21 Aug 2017

\section{ABSTRACT}

Introduction: Alginate is a natural substance derived from the brown seaweed. Alginate scaffold as a biomaterial has numerous applications in tissue engineering. It has favorable properties such as biocompatibility and highly porous scaffold organization and provides mechanical framework for cells. Furthermore, alginate hydrogel has been used as an injectable vehicle for cell culture or drug delivery. Alginate scaffold can fill cavities in the injured brain and spinal cord and provide the framework for regrowth and attachment of axons. Conclusion: Alginate scaffold maintains structural similarity to the extracellular matrices in different tissues. By proper manipulation of alginate structure, it may play several critical roles in neural tissue engineering.

\section{Key words:}

1. Biocompatible Materials

2. Hydrogel

3. Tissue Engineering

*Corresponding Author: Zahra Khosravizadeh

E-mail: zahra.khosravizadeh@yahoo.com 
كاربرد داربست آلزينات در مهيندسى بافت عصبى

\author{
مريم برهانى حقيقى ז'، شهناز رضوى"، زهرا خسروى زاده"” \\ 'مركز تحقيقات علوم اعصاب شفا، بيمارستان خاتمالانبياء، تهران، ايران

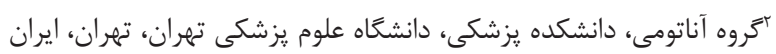

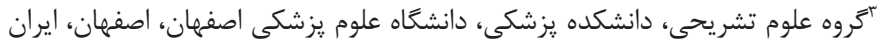

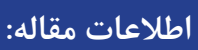

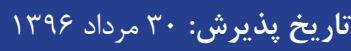

اصلاحيه: VV ارديبهشت عوسات مقاله:

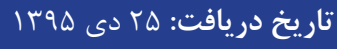

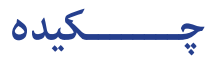

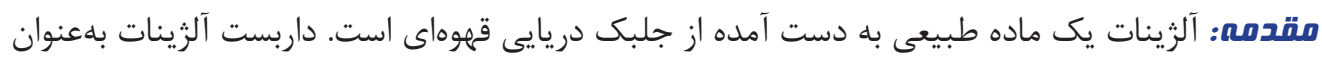

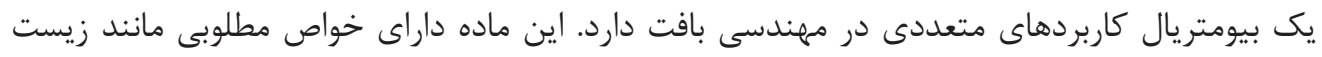

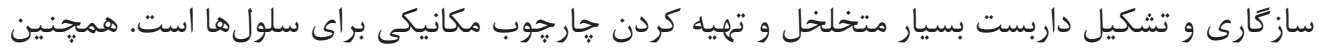

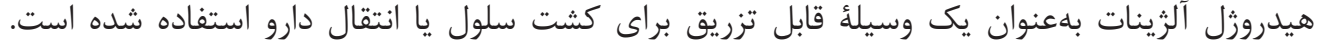

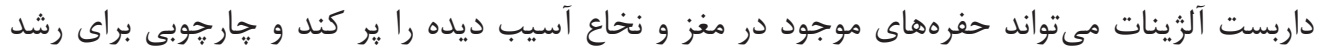

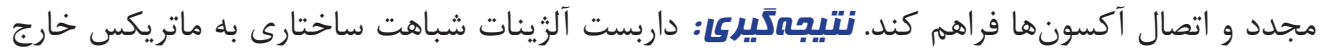

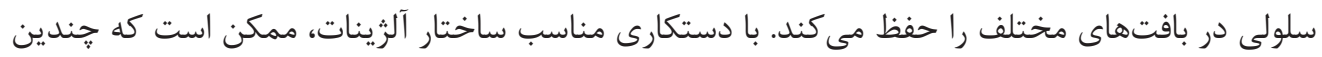
نقش حياتى در مهندسى بافت عصبى بازى كنداف

\footnotetext{
كليد وارهها:

1 إ. بيومتريال

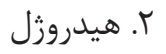

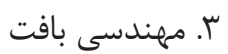

" نويسنده مسئول: زهرا خسروى زاده آدرس الكترونيكى: zahra.khosravizadeh@yahoo.com 


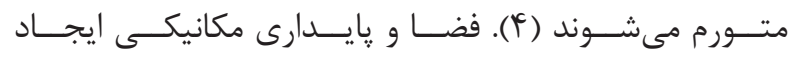

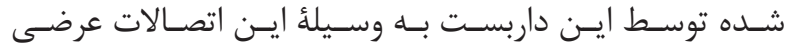

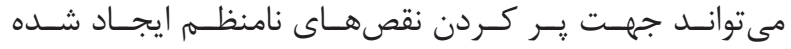

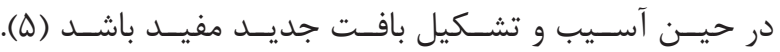
هEG

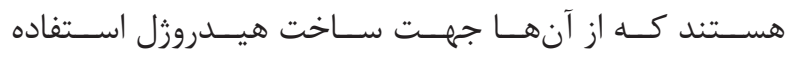

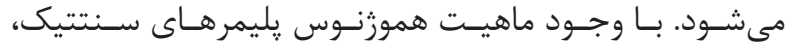

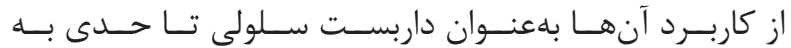

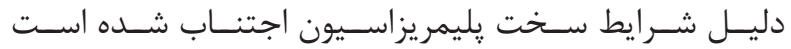

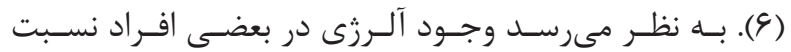

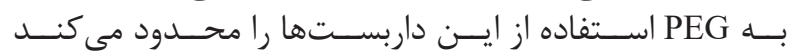

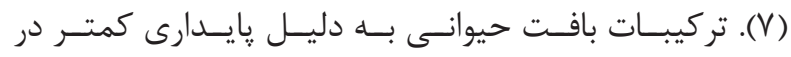

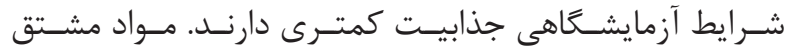

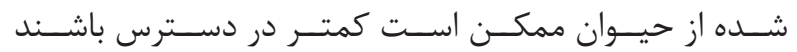

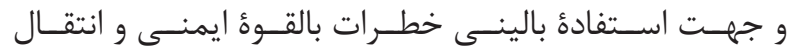

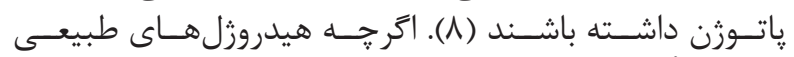

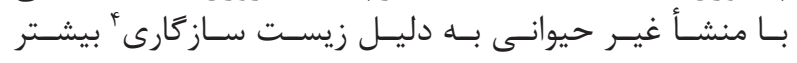

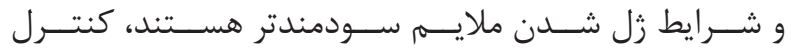

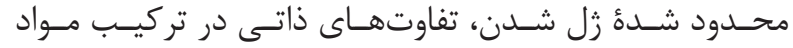

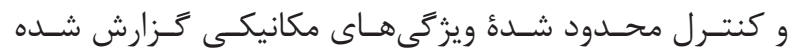

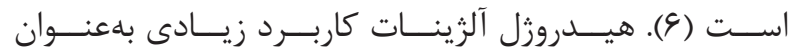

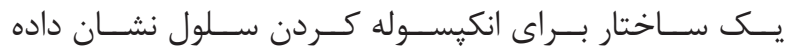

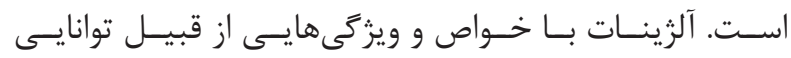

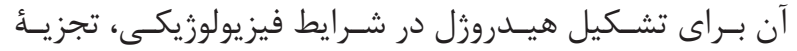

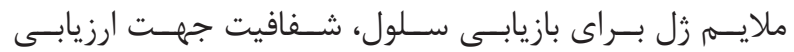

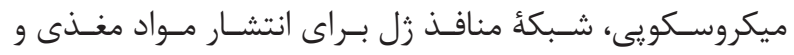

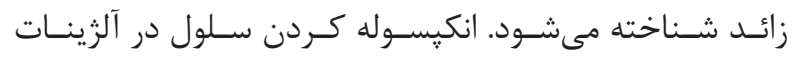

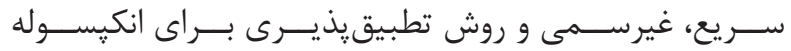

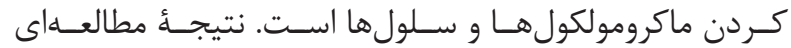

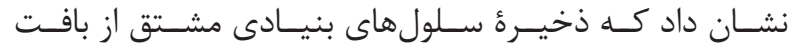

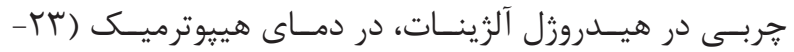

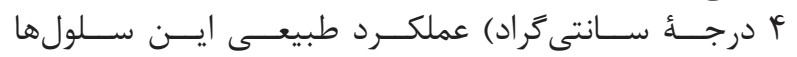

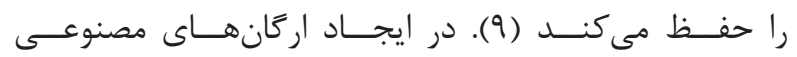

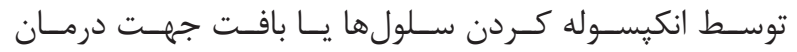

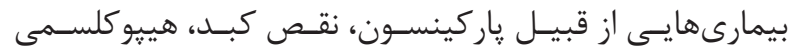

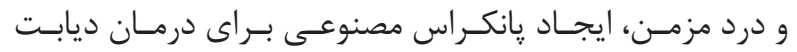

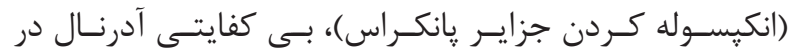

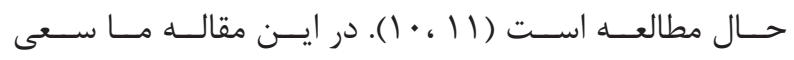

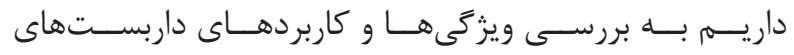

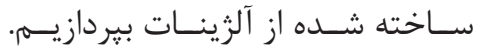

\section{معرفى آلثينات}

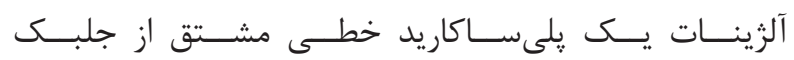

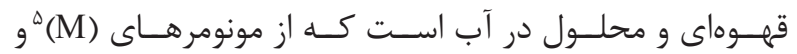

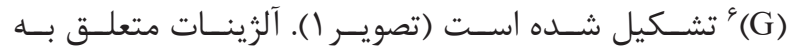

${ }^{1}$ Neurodegenerative diseases

${ }^{2}$ Eextracellular matrix

${ }^{3}$ Poly (ethylene glycol)

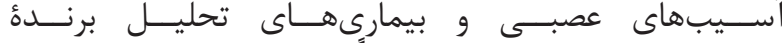

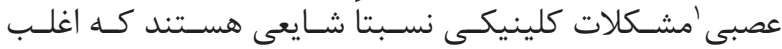

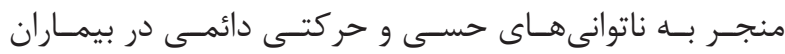

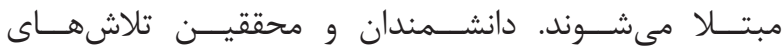

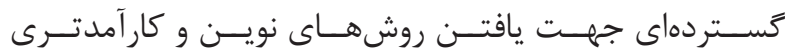

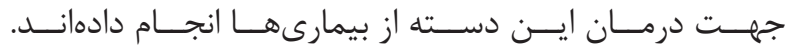

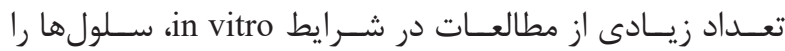

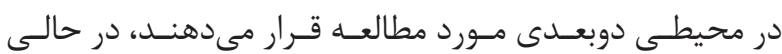

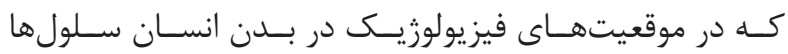

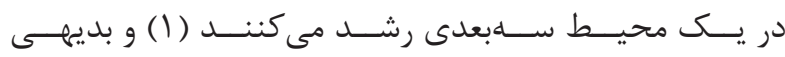

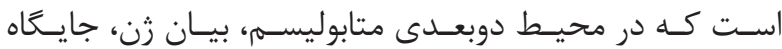

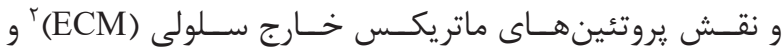

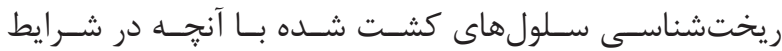

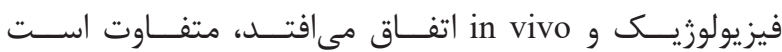

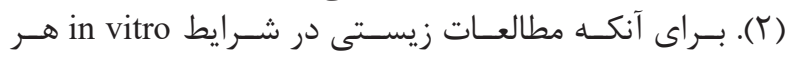

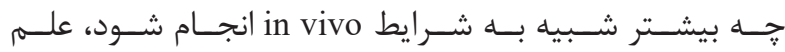

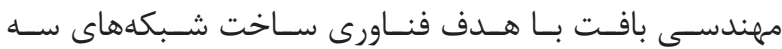

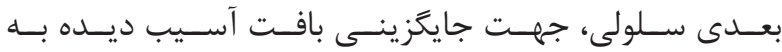

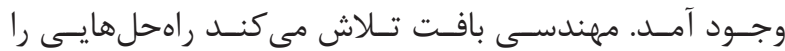

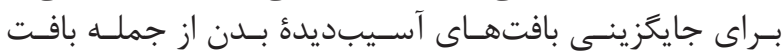

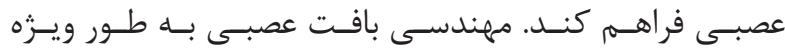

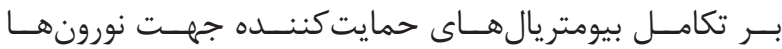

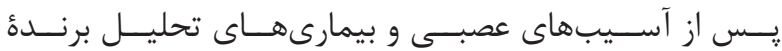

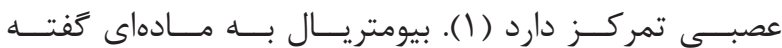

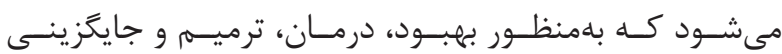

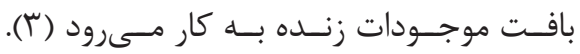

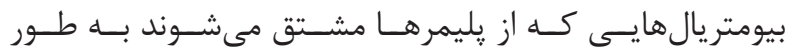

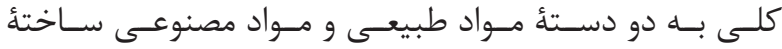

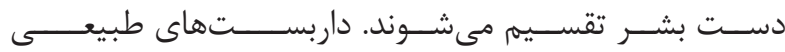

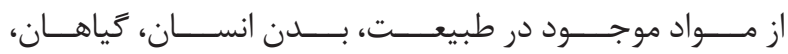

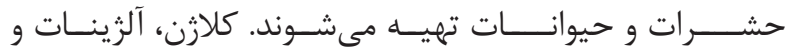

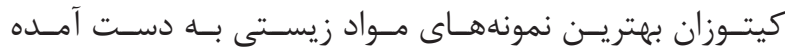

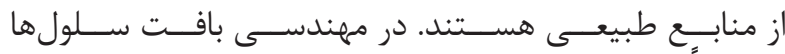

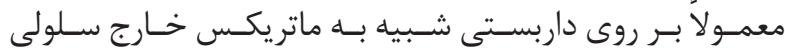

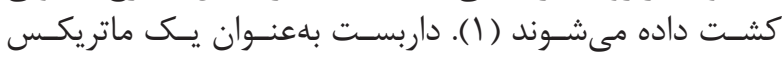

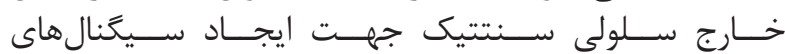

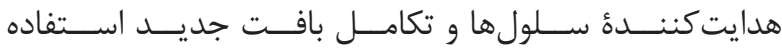

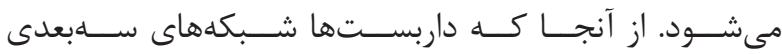

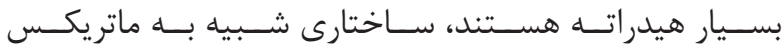

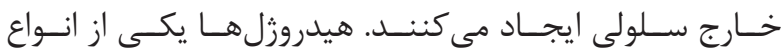

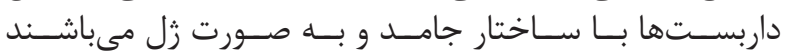

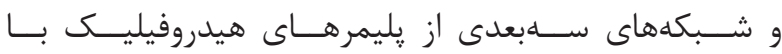

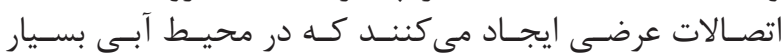

\footnotetext{
${ }^{4}$ Biocompatibility

${ }^{5} \mathrm{D}$-mannuronicacid

${ }^{6} \mathrm{~L}$-guluronicacid
} 


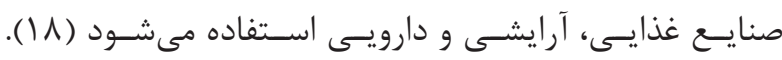

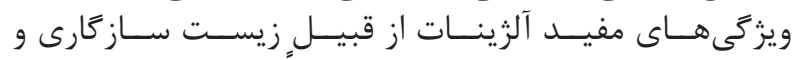

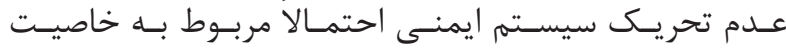

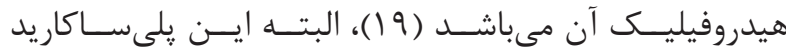

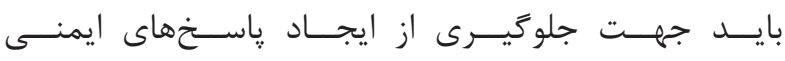

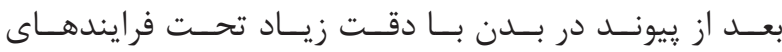

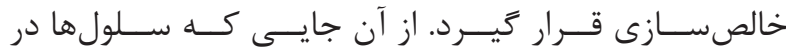

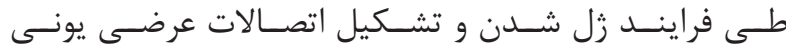

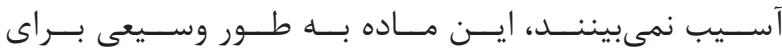

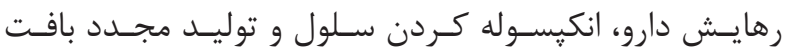

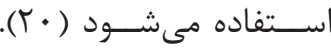

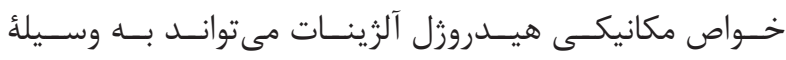

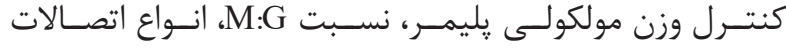

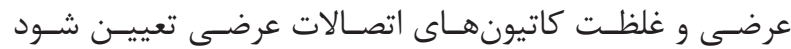

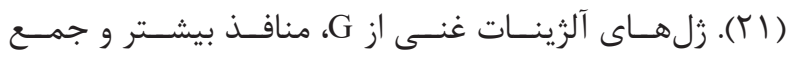

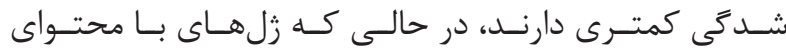

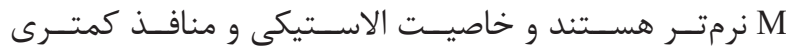

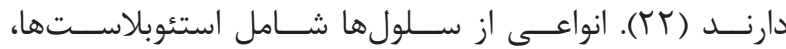

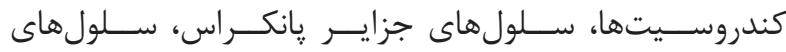

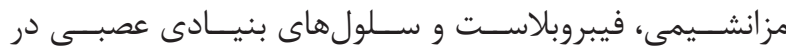

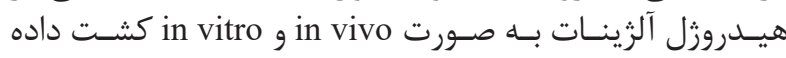

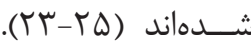

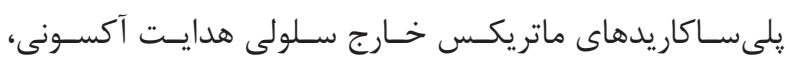

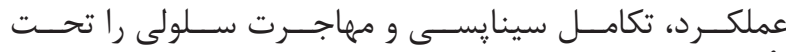

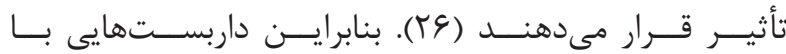

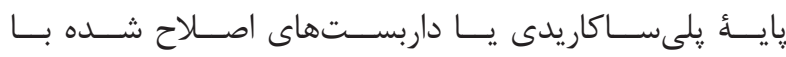

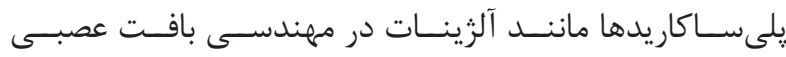

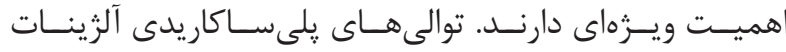

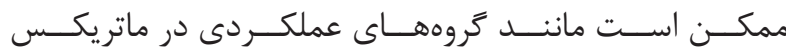

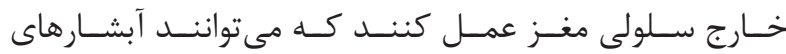

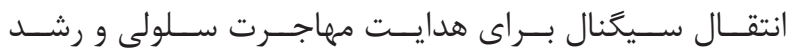

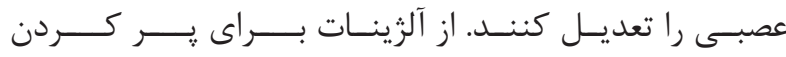

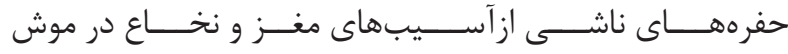

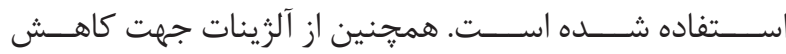

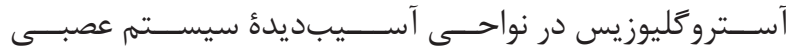

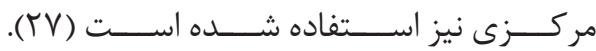

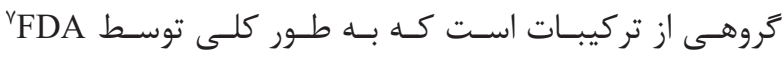

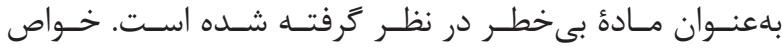

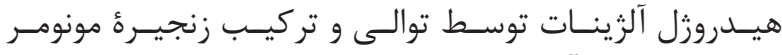

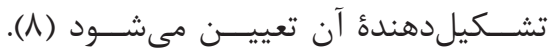

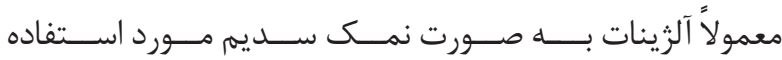

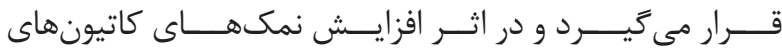

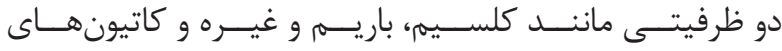

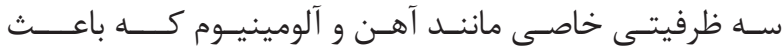

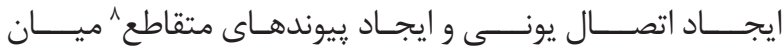

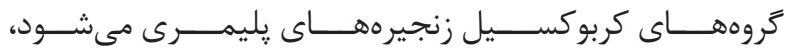

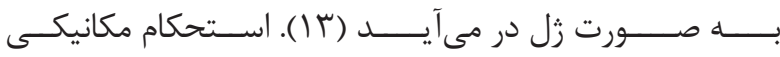

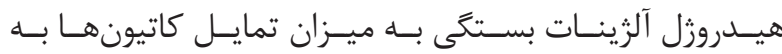

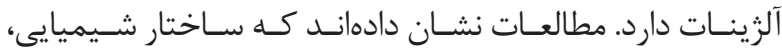

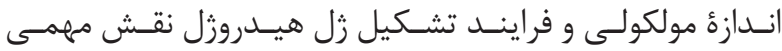

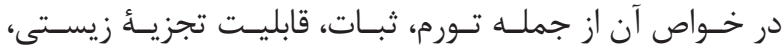

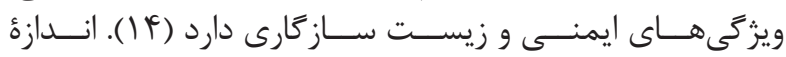

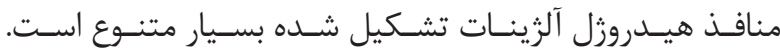

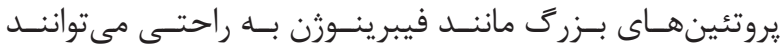

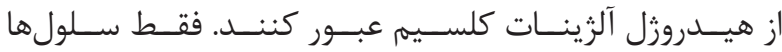

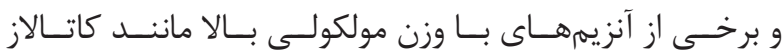

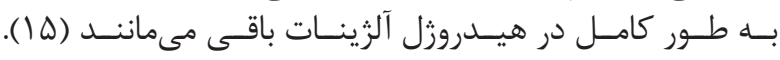

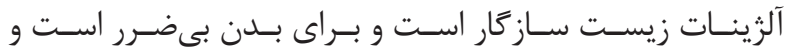

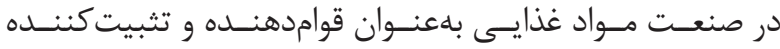

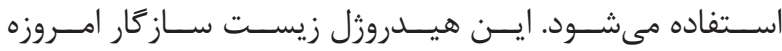

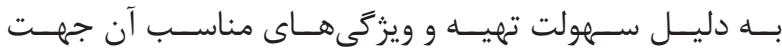

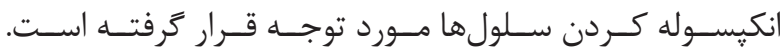

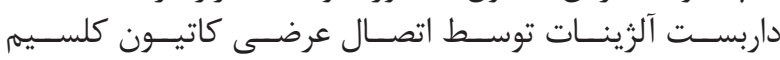

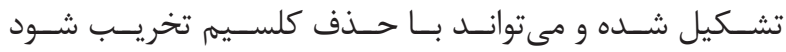

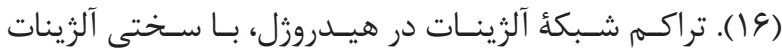

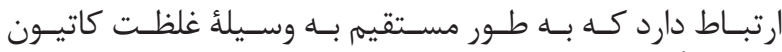

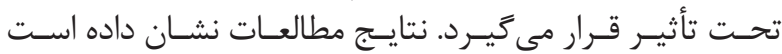

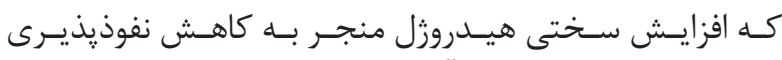

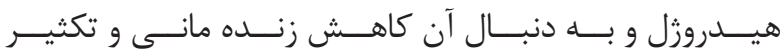

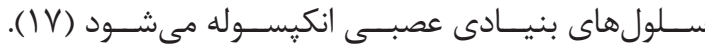

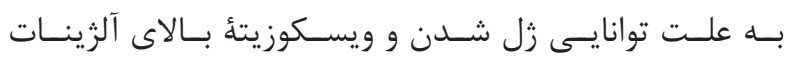

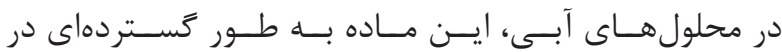

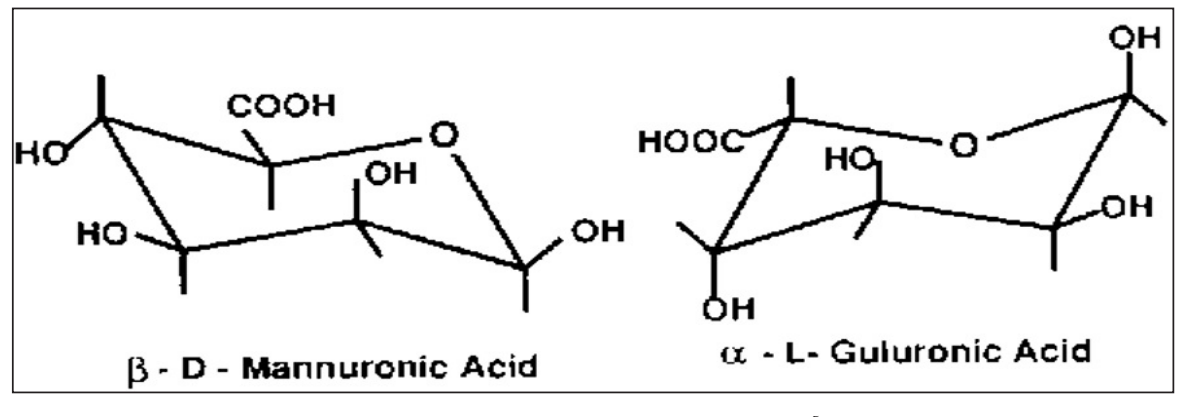

تصوير ا- واحدهاى تشكيلدهندة اسيد آلرينيك (r)).

${ }^{7}$ Food and drug administration

${ }^{8}$ Cross linking 


\section{خواص و اشكال هيدروزل}

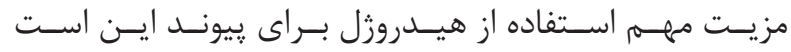

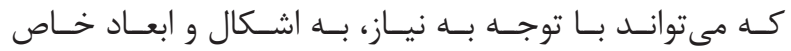

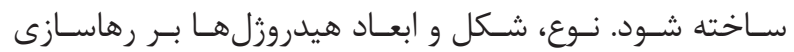

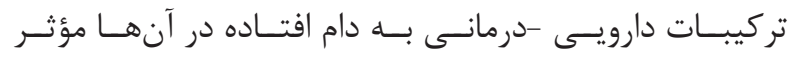

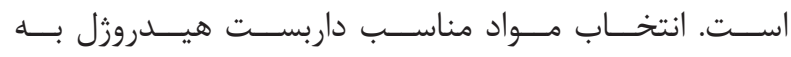

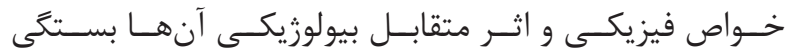

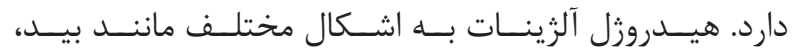

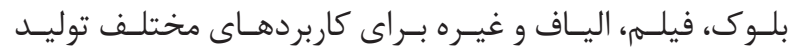

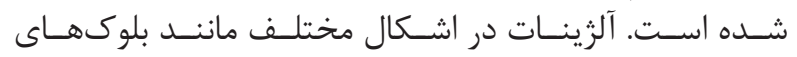

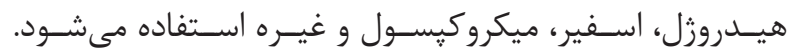

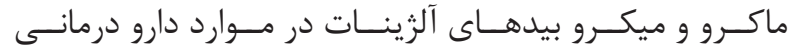

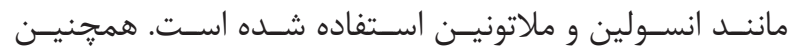

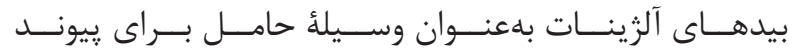

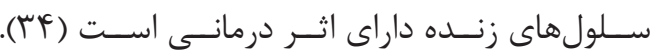
مشخصات فيزيكى داربست آلزينات

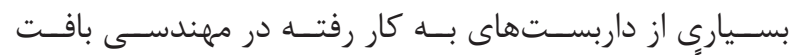

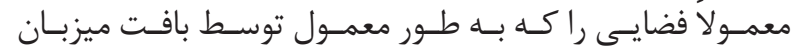

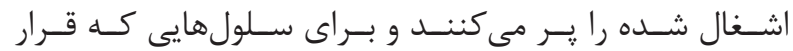

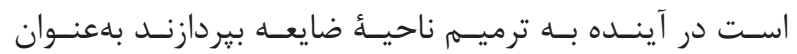

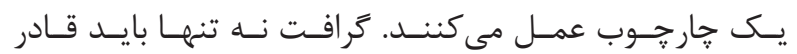

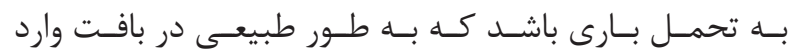

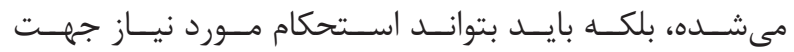

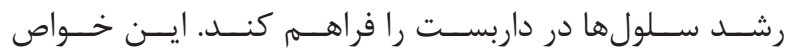

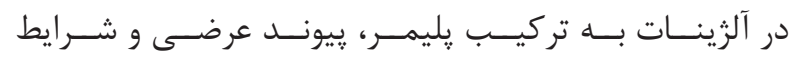

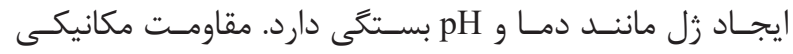

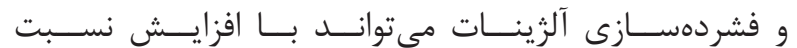
$\beta$-(1-4)-linked بـ $\alpha$-(1-4)- linked L-guluronic acid (G) G و يـا بـا افزايـش طـول قطعـات (1) (D-mannuronic acid (M

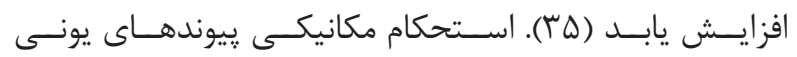

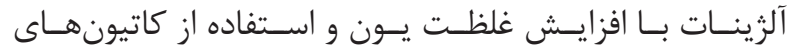

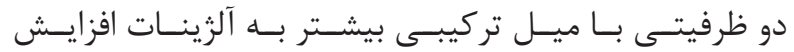

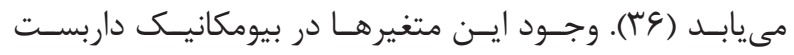

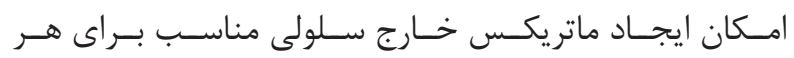

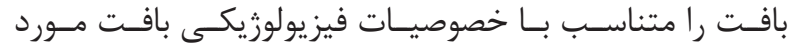

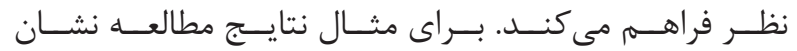

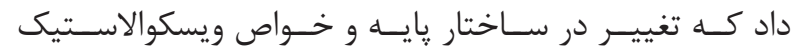

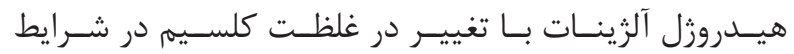

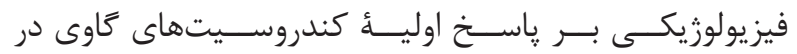

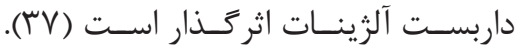

ويثزى ها و قابليت انتقال مواد توسط آلثينات

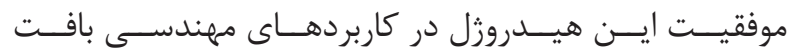

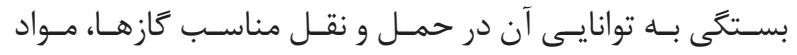

${ }^{9}$ Dulbecco's modified eagle medium/nutrient mixture F-12 ${ }^{10}$ Fibroblast growth factor 2

${ }^{11}$ Eepidermal growth factor
و و همــكاران ســلولهاى بنيـادى عصبــى را در

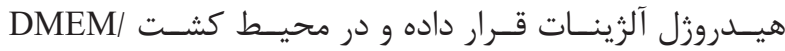

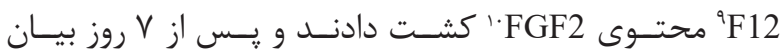

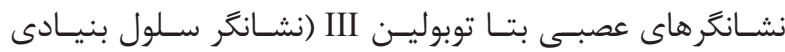

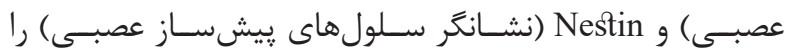

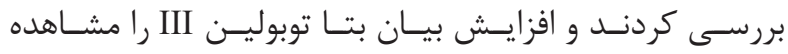

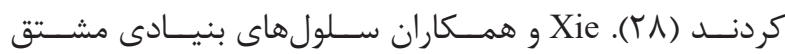

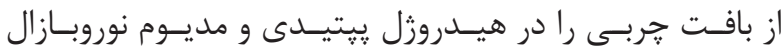

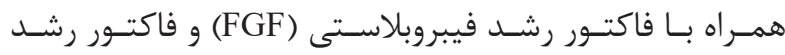

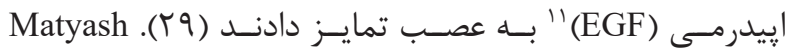

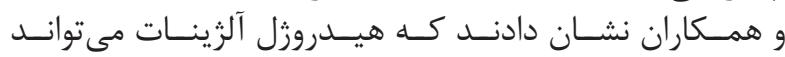

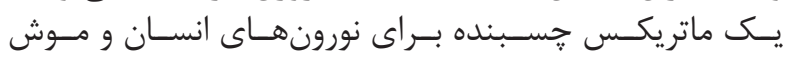

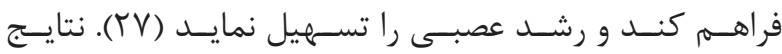

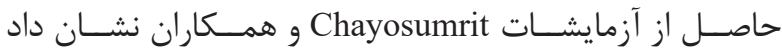

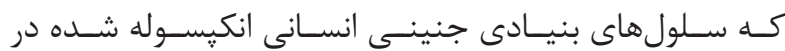

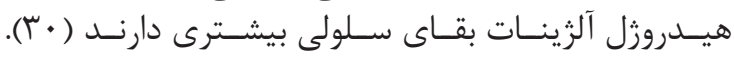

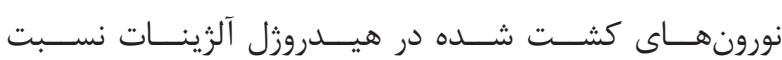

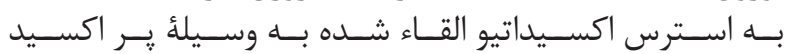

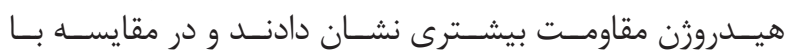

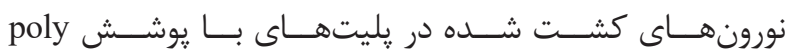
L-lysine

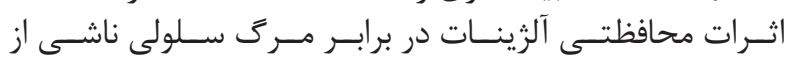

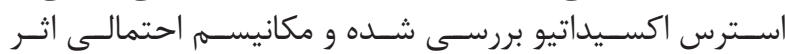

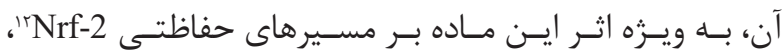

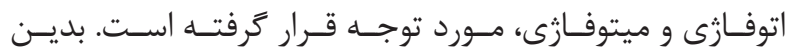

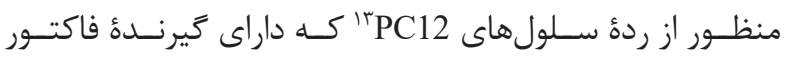

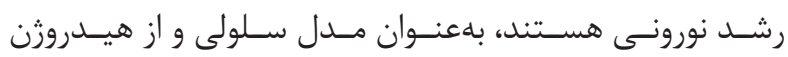

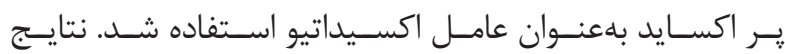

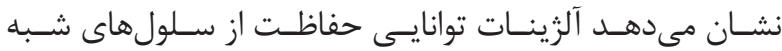

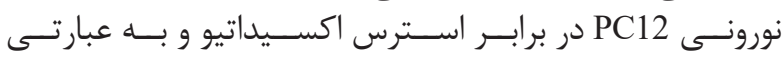

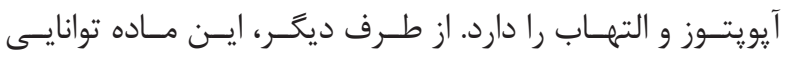

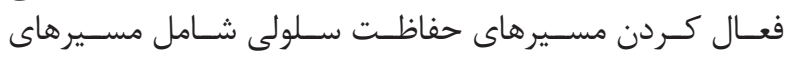

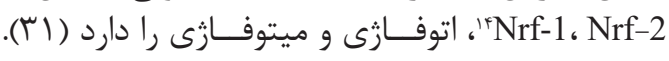

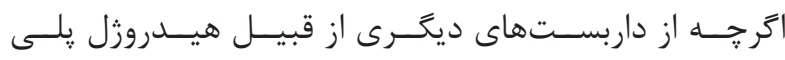

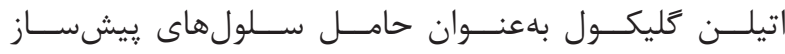

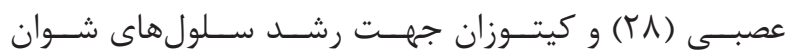

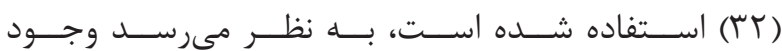

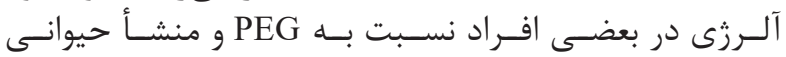

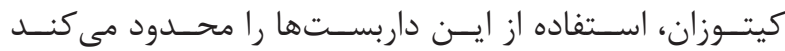

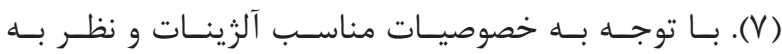

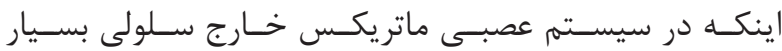

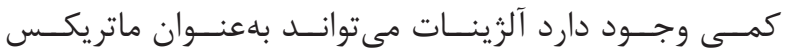

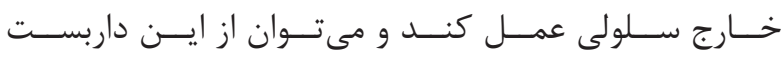

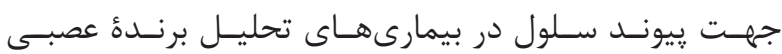

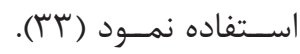

${ }^{12}$ Nuclear factor erythroid 2-related factor 2

${ }^{13}$ Pheochromocytoma cell

${ }^{14}$ Nuclear respiratory factor 1 


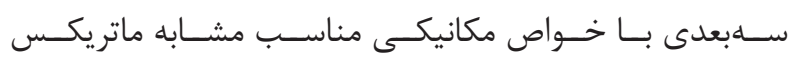

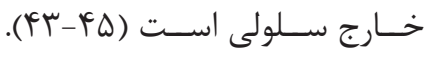

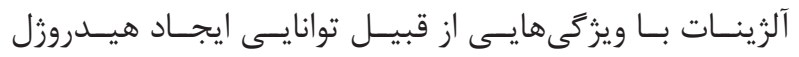

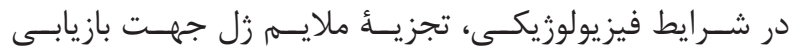

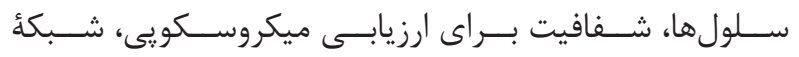

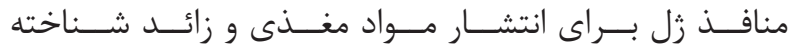

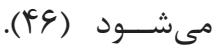

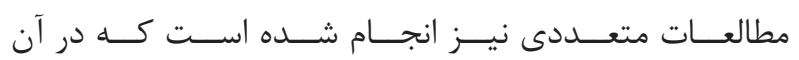

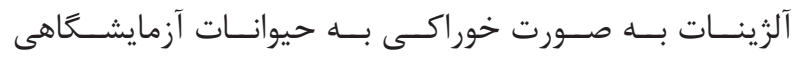

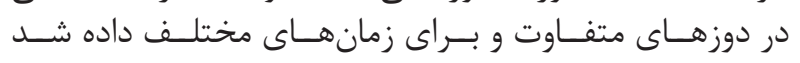

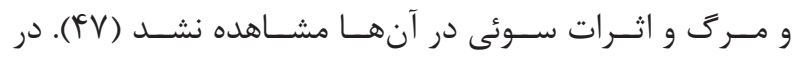

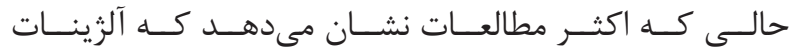

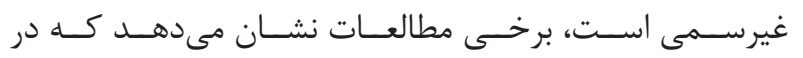

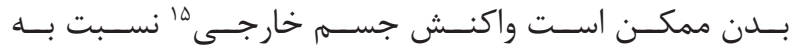

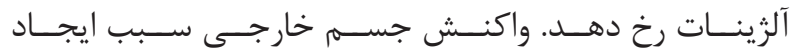

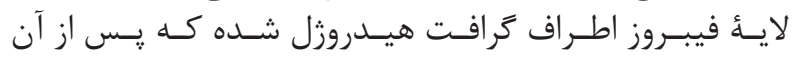

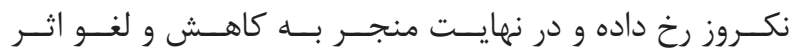

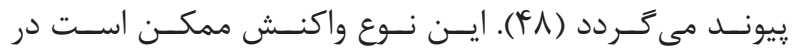

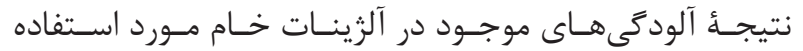

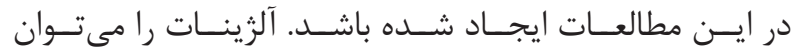

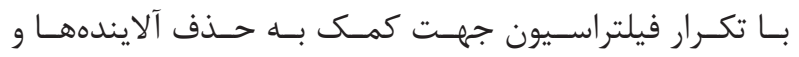

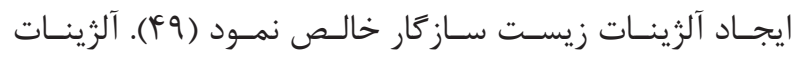

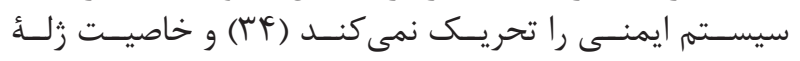

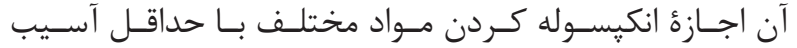

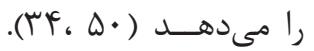

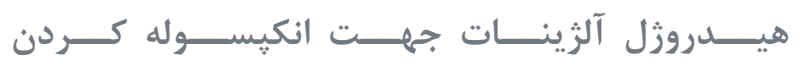

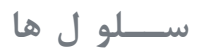

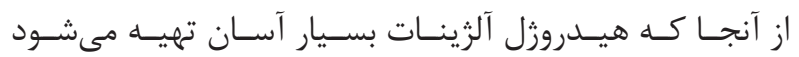

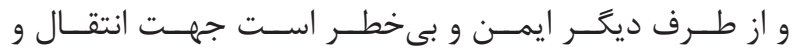

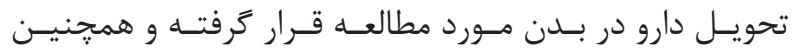

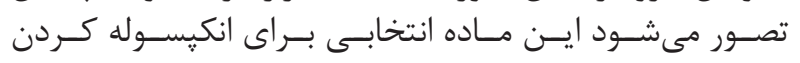

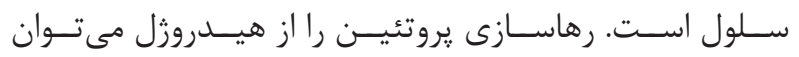

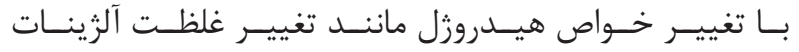

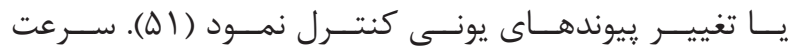

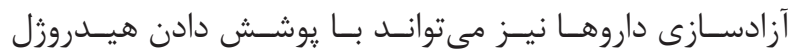

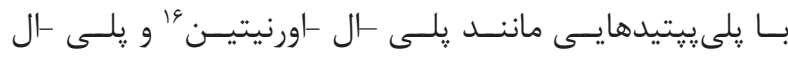

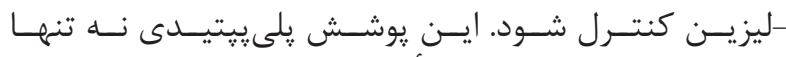

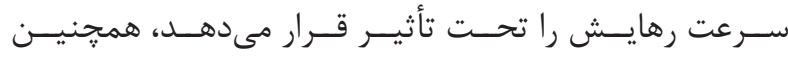

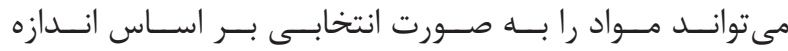

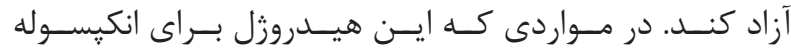

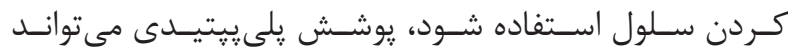

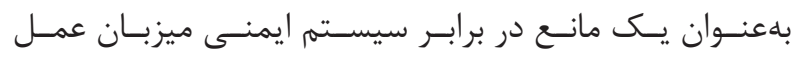

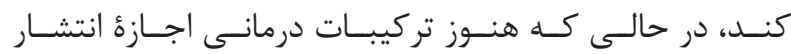

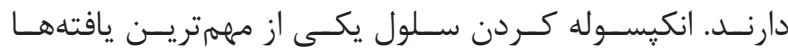

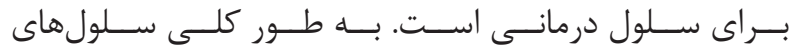

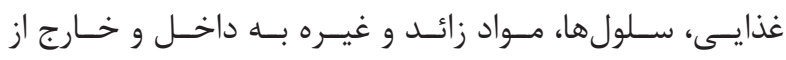

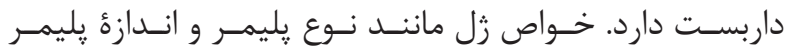

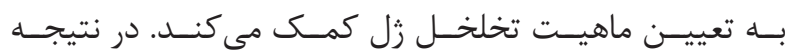

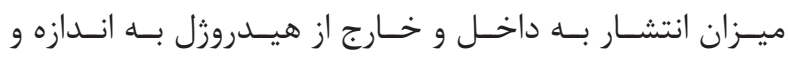

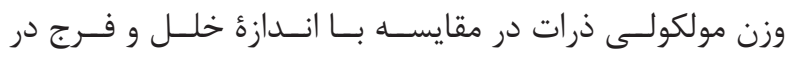

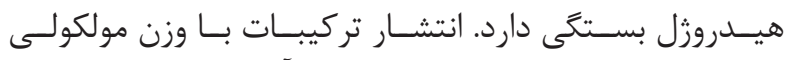

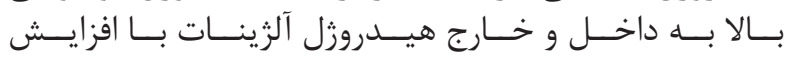

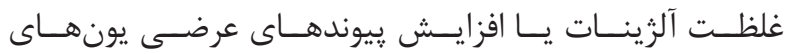

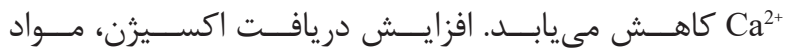

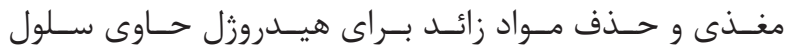

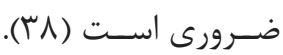
ويثزَى هاى بيولوزيكى آلزينات

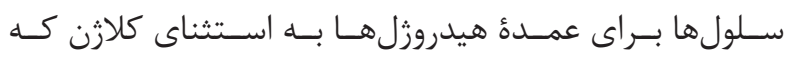

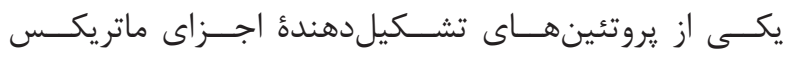

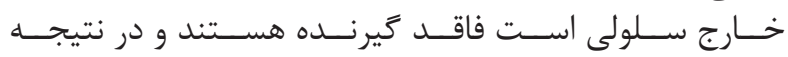

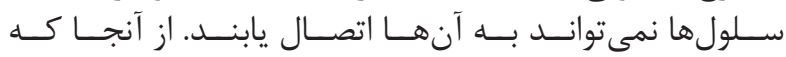

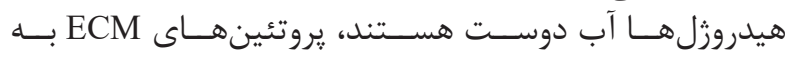

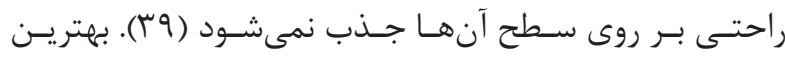

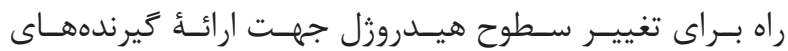

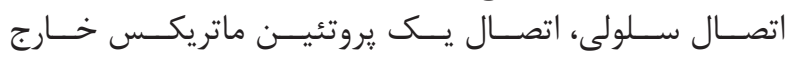

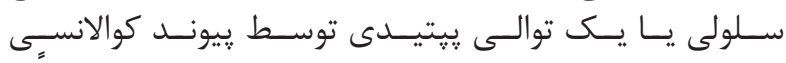

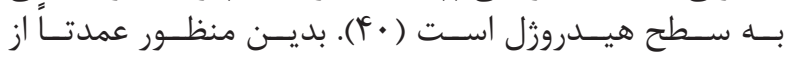

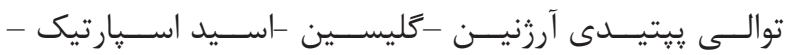

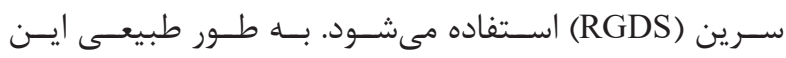

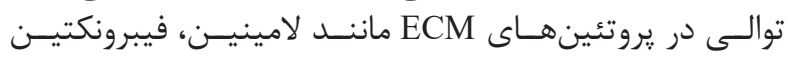

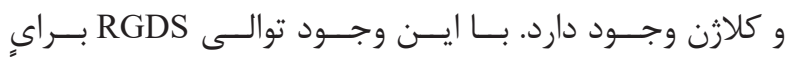

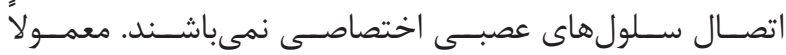

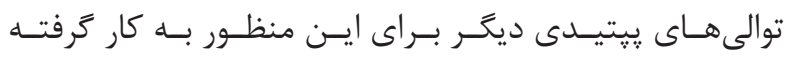

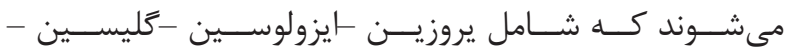

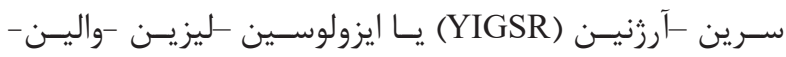

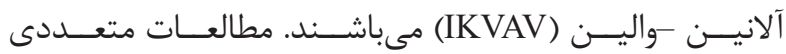

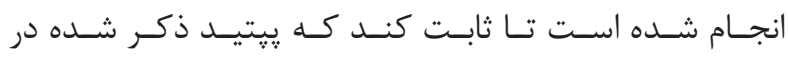

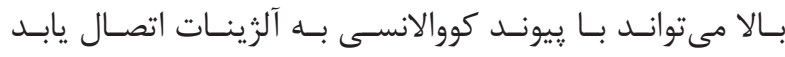

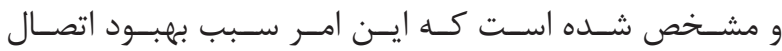

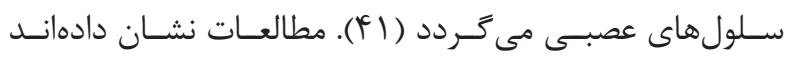

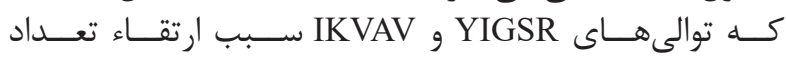

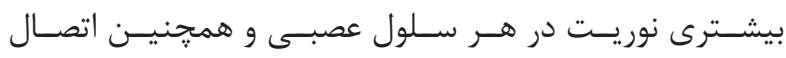

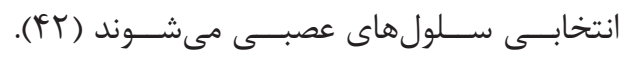
زيست سازكارى آلزينات

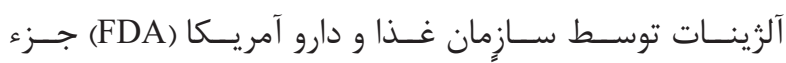

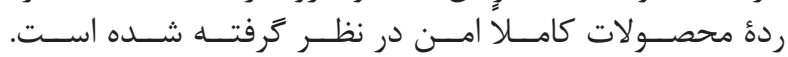

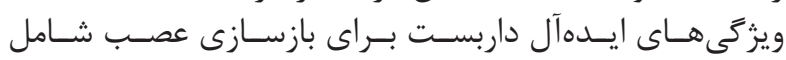

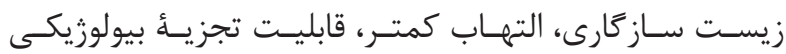

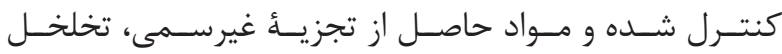

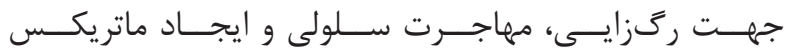




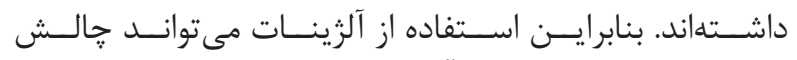

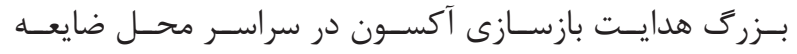

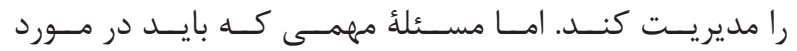

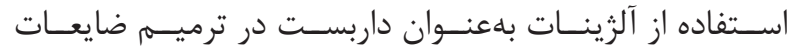

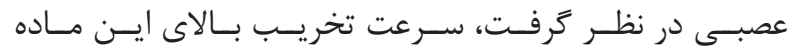

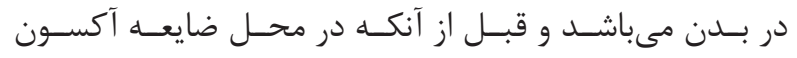

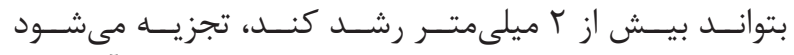

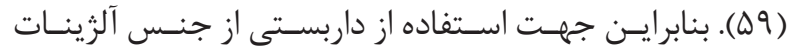

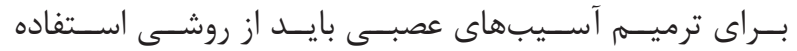

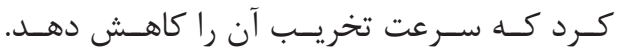

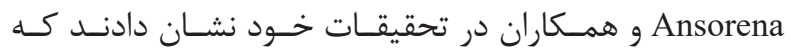

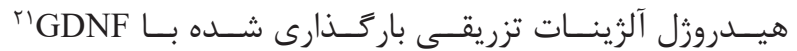

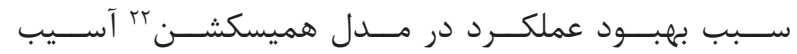

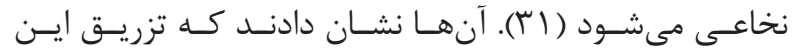

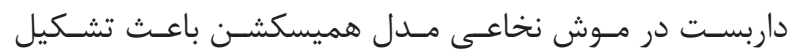

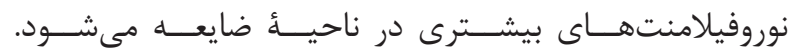

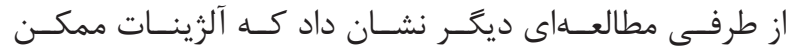

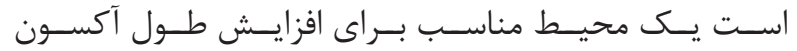
نخـاع فراهـم كنــد (•) (9).

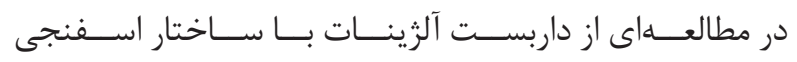

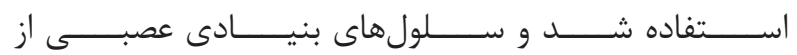

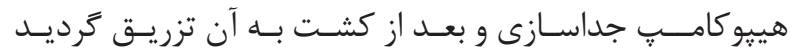

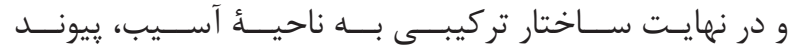

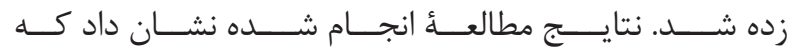

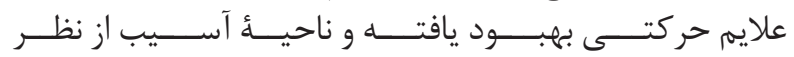

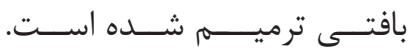

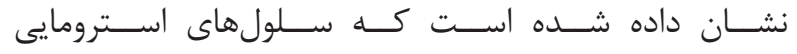

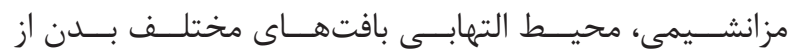

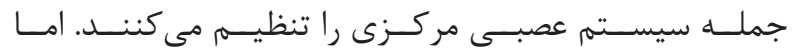

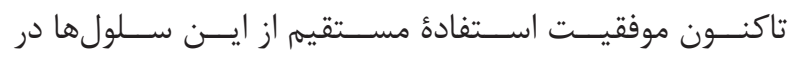

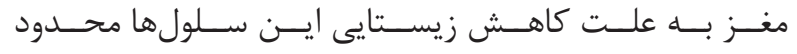

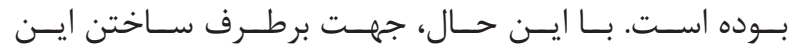

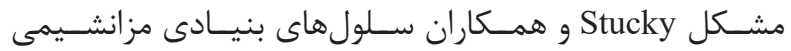
(MSC)

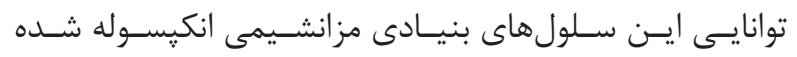

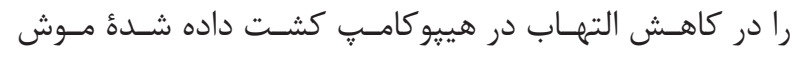

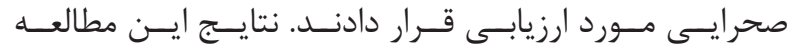

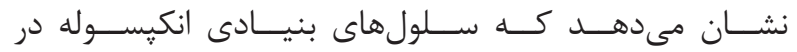

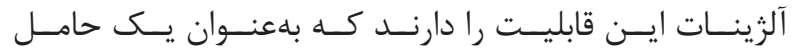

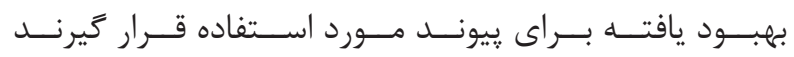

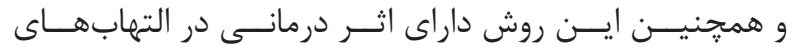

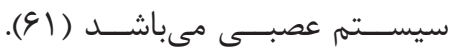

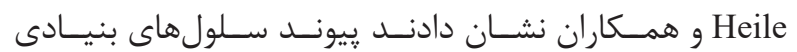

${ }^{17}$ Neural progenitor cells

${ }^{18}$ Poly lactid-co-glycolide alginate lyase

${ }^{19}$ Glial fibrillary acidic protein

${ }^{20}$ Microtubule-associated protein 2

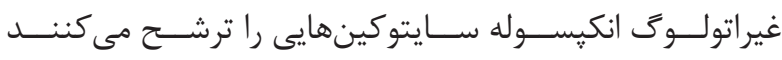

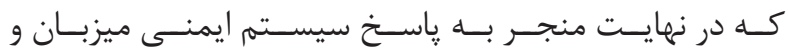

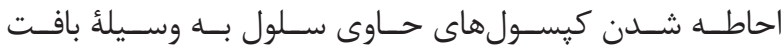

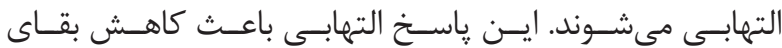

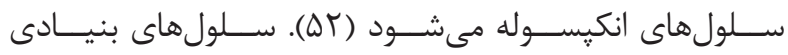

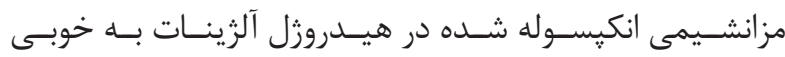

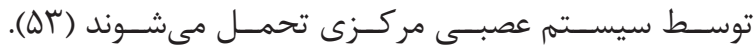

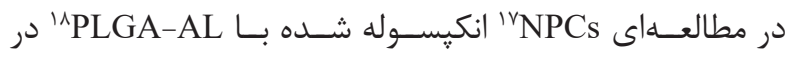

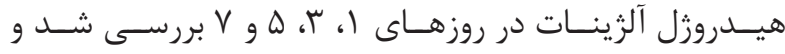

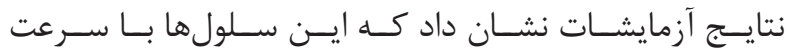

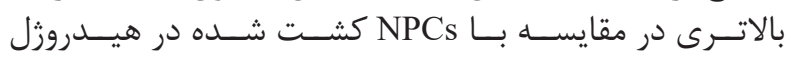

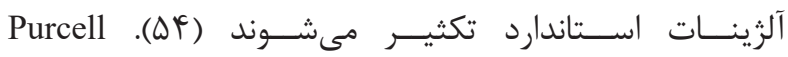

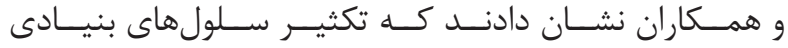

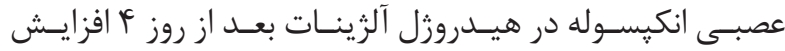

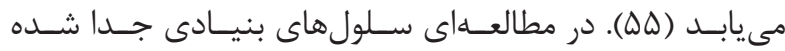

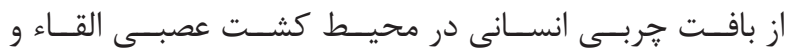

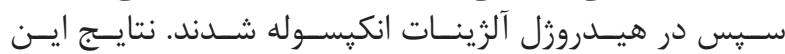

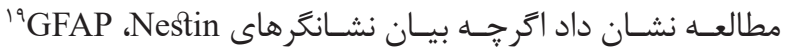

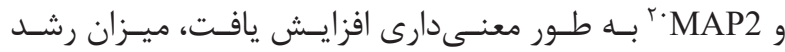

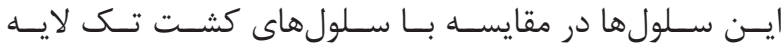

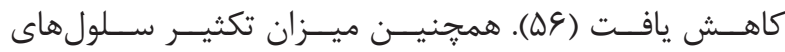

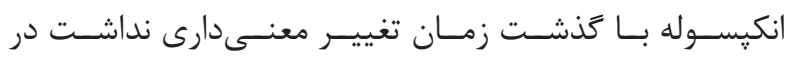

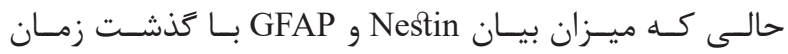

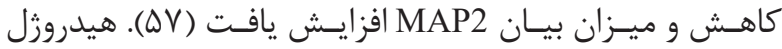

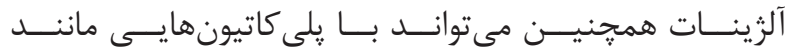

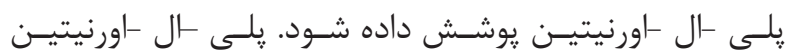

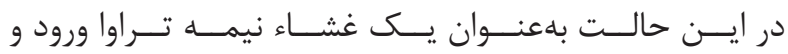

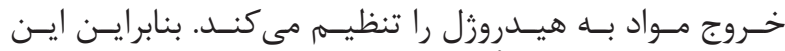

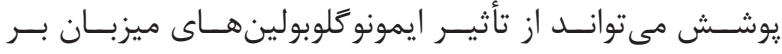

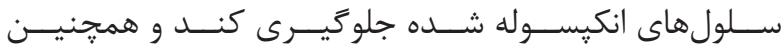

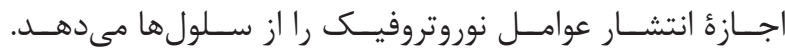

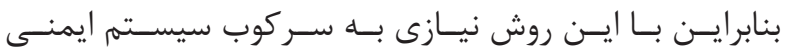

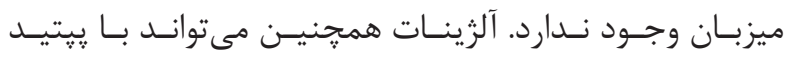

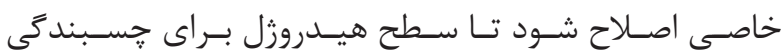

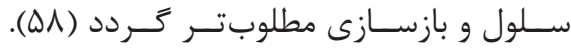

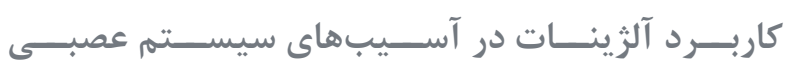

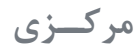

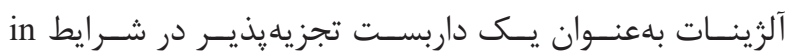

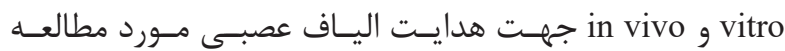

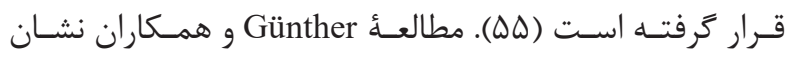

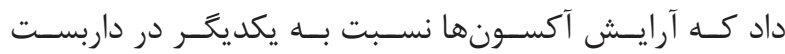

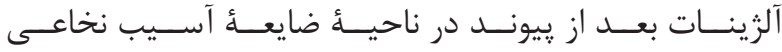

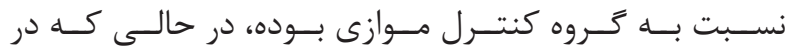

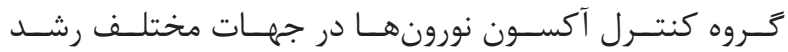

${ }^{21}$ Glial cell-derived neurotrophic factor

${ }^{22}$ Hemi section

${ }^{23}$ Mesenchymal stem cell 
جدول ا- خلاصؤ برخى مطالعات انجام شده در مورد كاربرد هيدروزل آلرينات در مهندسى بافت عصبى.

\begin{tabular}{|c|c|c|c|}
\hline 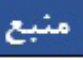 & نتيجه & نوع سلول & نوع داربست \\
\hline 11 & 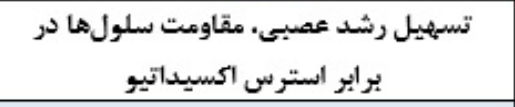 & 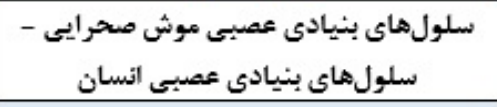 & هيدرورّل آلرينات \\
\hline 19 & اقزايش بيان ثشانكر عصبى III بتا توبولين & سلولهاى بنيادى عصبى موش صحرايى & هيدرورل آلريثات \\
\hline$T T$ & افزايش تشكيل نوروفيلامنت در ناحية آسيب & - & $\begin{array}{c}\text { آلريثات - GDNF } \\
\text {-هيدرورثل }\end{array}$ \\
\hline rA & سرعت بالاتر تكثير سلولى & سلولهاى يَيش ساز عصبي موش صحرايى & آلريثات PLGA-AL \\
\hline rq & افزايش عيزان تكثير سلولى & سلولهاى بنيادى عصبي موش & هيدرورل آلريثات \\
\hline$f_{+}$ & كاهش تكثير سلولى -افزايش بيان & سلولهاى بنيادى مشتق از باقت جربى & هيدرورل آلرينات \\
\hline$P 1$ & $\begin{array}{l}\text { كاهش بيان Nestin و اقزايش بيان MAP2 } \\
\text { MAP2 }\end{array}$ & سلولهاى بنيادى مشتق از بافت جربى انسان & هيدرورل آلرينات \\
\hline FT & يشيبرد بازسازى آكيسون در طناب نخاعى ديده در موش & سلولهاى بنيادى مشتق از مغز استخوان & هيدرورل آلرينات \\
\hline$P Q$ & كاهش م و و كاهش عيزان التيهاب عصيى & سلولهاى بنيادى مز انشيمى عوش صحرايى & هيدرورل آلريثات \\
\hline PQ & 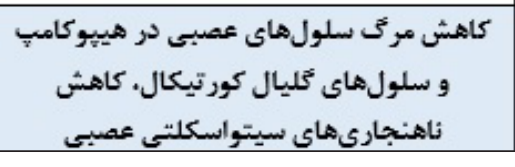 & سلولهاى بشيادى مزٔانشيمى عوش صحرايى & هيدرورل آلرينات \\
\hline
\end{tabular}

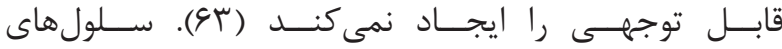

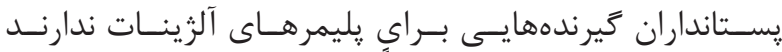

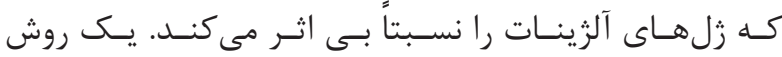

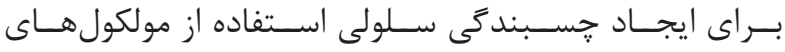

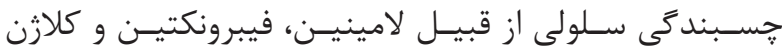

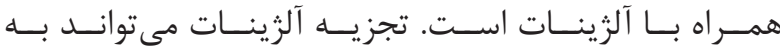

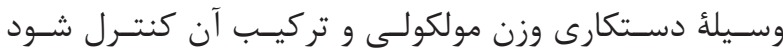

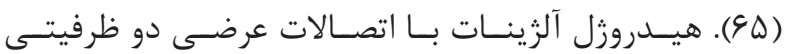

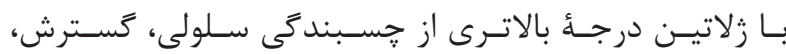

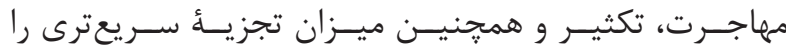

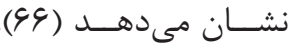

بــا توجــه بــه راهبــرد اسـتفاده از مولكول هايـى بــا ســاختار

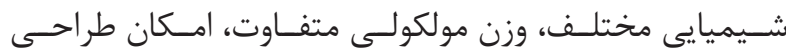

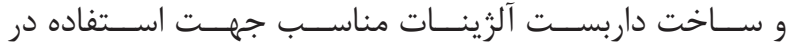

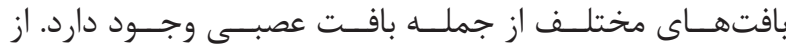

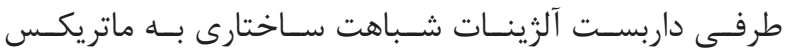

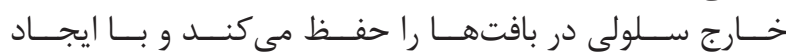

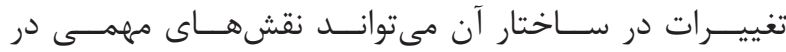

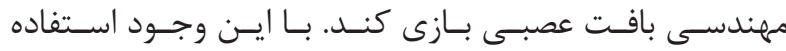

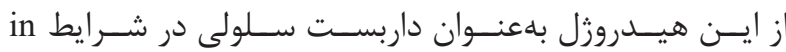

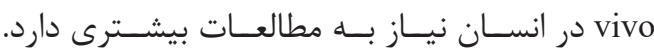

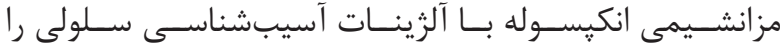

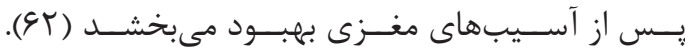
نتيجه كيرى

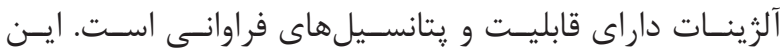

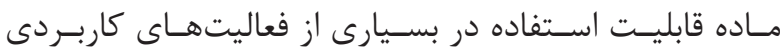

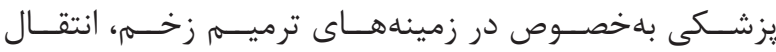

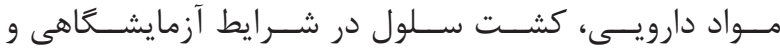

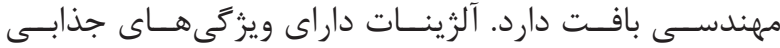

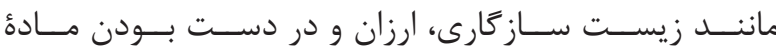

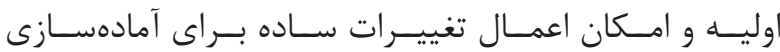

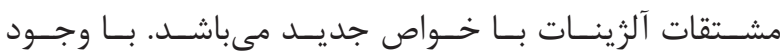

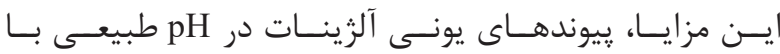

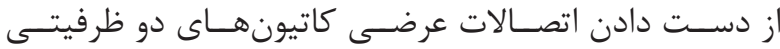

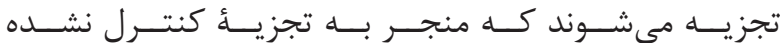

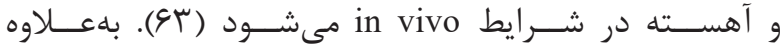

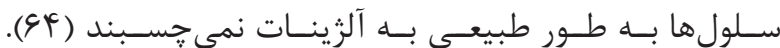

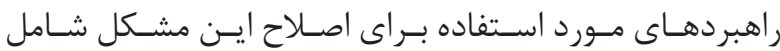

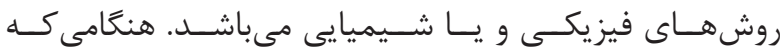

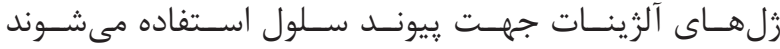

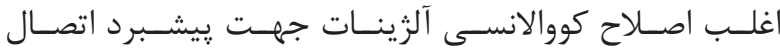

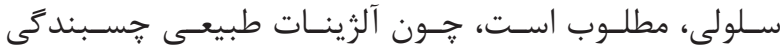


1. Hunt N, Smith AM, Gbureck U, Shelton R, Grover L. Encapsulation of fibroblasts causes accelerated alginate hydrogel degradation. Acta Biomater. 2010; 6(9): 3649-56.

2. Dutta RC, Dutta AK. Cell-interactive 3D-scaffold; advances and applications. Biotechnol Adv. 2009; 27(4): 334-9.

3. Garg T, Goyal AK. Biomaterial-based scaffoldscurrent status and future directions. Expert Opin Drug Deliv. 2014; 11(5): 767-89.

4. Hunt JA, Chen R, van Veen T, Bryan N. Hydrogels for tissue engineering and regenerative medicine. Journal of Materials Chemistry B. 2014; 2(33): 5319-38.

5. Lam J, Clark EC, Fong EL, Lee EJ, Lu S, Tabata $\mathrm{Y}$, et al. Data describing the swelling behavior and cytocompatibility of biodegradable polyelectrolyte hydrogels incorporating poly (L-lysine) for applications in cartilage tissue engineering. Data Brief. 2016; 7: 614-9.

6. Lee J, Cuddihy MJ, Kotov NA. Three-dimensional cell culture matrices: state of the art. Tissue Eng Part B Rev. 2008; 14(1): 61-86.

7. Wenande E, Garvey LH. Immediate-type hypersensitivity to polyethylene glycols: a review. Clin Exp Allergy. 2016; 46(7): 907-22.

8. Lee KY, Mooney DJ. Alginate: properties and biomedical applications. Progress in Polymer Science. 2012; 37(1): 106-26

9. Swioklo S, Constantinescu A, Connon CJ. Alginate-encapsulation for the improved hypothermic preservation of human adipose-derived stem cells. Stem Cells Transl Med. 2016; 5(3): 339-49.

10. Andersen T, Auk-Emblem P, Dornish M. 3D cell culture in alginate hydrogels. Microarrays. 2015; 4(2): 133-61.

11. Balyura M, Gelfgat E, Ehrhart-Bornstein M, Ludwig B, Gendler Z, Barkai U, et al. Transplantation of bovine adrenocortical cells encapsulated in alginate. Proceedings of the National Academy of Sciences. 2015; 112(8): 2527-32.

12. Gacesa P, Russell N. The structure and properties of alginate. Pseudomonas Infection and Alginates. 1990; 29-49.

13. Castilho M, Rodrigues J, Pires I, Gouveia B, Pereira
M, Moseke C, et al. Fabrication of individual alginateTCP scaffolds for bone tissue engineering by means of powder printing. Biofabrication. 2015; 7(1): 015004

14. Bregman BS, Kunkel-Bagden E, Schnell L, Dai HN, Gao D, Schwab ME. Recovery from spinal cord injury mediated by antibodies to neurite growth inhibitors. Nature. 1995; 378(6556): 498-501.

15. Maiti UN, Lim J, Lee KE, Lee WJ, Kim SO. Threedimensional shape engineered, interfacial gelation of reduced graphene oxide for high rate, large capacity supercapacitors. Advanced Materials. 2014; 26(4): $615-9$.

16. Li X, Liu T, Song K, Yao L, Ge D, Bao C, et al. Culture of neural stem cells in calcium alginate beads. Biotechnology Progress. 2006; 22(6): 1683-9.

17. Banerjee A, Arha M, Choudhary S, Ashton RS, Bhatia SR, Schaffer DV, et al. The influence of hydrogel modulus on the proliferation and differentiation of encapsulated neural stem cells. Biomaterials. 2009; 30(27): 4695-9.

18. Li X, Feng J, Zhang R, Wang J, Su T, Tian Z, et al. Quaternized chitosan/alginate-fe3o4 magnetic nanoparticles enhance the chemosensitization of multidrug-resistant gastric carcinoma by regulating cell autophagy activity in mice. J Biomed Nanotechnol. 2016; 12(5): 948-61.

19. Chen C-Y, Ke C-J, Yen K-C, Hsieh H-C, Sun J-S, Lin F-H. 3D porous calcium-alginate scaffolds cell culture system improved human osteoblast cell clusters for cell therapy. Theranostics. 2015; 5(6): 643-55.

20. Haseeb MT, Hussain MA, Yuk SH, Bashir S, Nauman M. Polysaccharides based superabsorbent hydrogel from Linseed: Dynamic swelling, stimuli responsive on-off switching and drug release. Carbohydr Polym. 2016; 136: 750-6.

21. Mallardi A, Angarano V, Magliulo M, Torsi L, Palazzo G. General approach to the immobilization of glycoenzyme chains inside calcium alginate beads for bioassay. Anal Chem. 2015; 87(22): 11337-44.

22. Kabu S, Gao Y, Kwon BK, Labhasetwar V. Drug delivery, cell-based therapies, and tissue engineering approaches for spinal cord injury. J Control Release. 2015; 219: 141-54.

23. Kim TH, An DB, Oh SH, Kang MK, Song HH, Lee JH. Creating stiffness gradient polyvinyl alcohol hydrogel using a simple gradual freezing-thawing 
method to investigate stem cell differentiation behaviors. Biomaterials. 2015; 40: 51-60.

24. Park M, Lee D, Hyun J. Nanocellulose-alginate hydrogel for cell encapsulation. Carbohydrate Polymers. 2015; 116: 223-8.

25. Wang X, Hao T, Qu J, Wang C, Chen H. Synthesis of thermal polymerizable alginate-GMA hydrogel for cell encapsulation. Journal of Nanomaterials. 2015; 2015: $1-8$.

26. Saha K, Keung AJ, Irwin EF, Li Y, Little L, Schaffer DV, et al. Substrate modulus directs neural stem cell behavior. Biophysical Journal. 2008; 95(9): 4426-38.

27. Matyash M, Despang F, Mandal R, Fiore D, Gelinsky $\mathrm{M}$, Ikonomidou C. Novel soft alginate hydrogel strongly supports neurite growth and protects neurons against oxidative stress. Tissue Engineering Part A. 2011; 18(12): 55-66.

28. Mahoney MJ, Anseth KS. Three-dimensional growth and function of neural tissue in degradable polyethylene glycol hydrogels. Biomaterials. 2006; 27(10): 2265-74.

29. Xie X, Tang Z, Chen J, Yang J, Zeng W, Liu N, et al. Neurogenesis of adipose-derived stem cells in hydrogel. J Huazhong Univ Sci Technolog Med Sci. 2011; 31(2): 174-7.

30. Chayosumrit M, Tuch B, Sidhu K. Alginate microcapsule for propagation and directed differentiation of hESCs to definitive endoderm. Biomaterials. 2010; 31(3): 505-14.

31. Ansorena E, De Berdt P, Ucakar B, Simón-Yarza T, Jacobs D, Schakman O, et al. Injectable alginate hydrogel loaded with GDNF promotes functional recovery in a hemisection model of spinal cord injury. International Journal of Pharmaceutics. 2013; 455(1): 148-58.

32. Yuan Y, Zhang P, Yang Y, Wang X, Gu X. The interaction of Schwann cells with chitosan membranes and fibers in vitro. Biomaterials. 2004; 25(18): 4273-8.

33. Rowley JA, Madlambayan G, Mooney DJ. Alginate hydrogels as synthetic extracellular matrix materials. Biomaterials. 1999; 20(1): 45-53.

34. Shapiro L, Cohen S. Novel alginate sponges for cell culture and transplantation. Biomaterials. 1997; 18(8): 583-90.

35. Desai RM, Koshy ST, Hilderbrand SA, Mooney DJ, Joshi NS. Versatile click alginate hydrogels crosslinked via tetrazine-norbornene chemistry. Biomaterials. 2015; 50: $30-7$.
36. Shahriari D, Koffler J, Lynam DA, Tuszynski MH, Sakamoto JS. Characterizing the degradation of alginate hydrogel for use in multilumen scaffolds for spinal cord repair. Journal of Biomedical Materials Research Part A. 2016; 104(3): 611-9.

37. Wan LQ, Jiang J, Arnold DE, Guo XE, Lu HH, Mow VC. Calcium concentration effects on the mechanical and biochemical properties of chondrocyte-alginate constructs. Cellular and Molecular Bioengineering. 2008; 1(1): 93-102.

38. Wu J, Kong T, Yeung KWK, Shum HC, Cheung $\mathrm{KMC}$, Wang L, et al. Fabrication and characterization of monodisperse PLGA-alginate core-shell microspheres with monodisperse size and homogeneous shells for controlled drug release. Acta Biomaterialia. 2013; 9(7): 7410-9.

39. Ng KW, Torzilli PA, Warren RF, Maher SA. Characterization of a macroporous polyvinyl alcohol scaffold for the repair of focal articular cartilage defects. Journal of Tissue Engineering and Regenerative Medicine. 2014; 8(2): 164-8

40. Khetan S, Guvendiren M, Legant WR, Cohen DM, Chen CS, Burdick JA. Degradation-mediated cellular traction directs stem cell fate in covalently crosslinked three-dimensional hydrogels. Nature Materials. 2013; 12(5): 458-65

41. Nakashima Y, Tsusu K, Minami K, Nakanishi Y. Development of a cell culture surface conversion technique using alginate thin film for evaluating effect upon cellular differentiation. Rev Sci Instrum. 2014; 85(6): 065004.

42. Tong Y, Shoichet M. Enhancing the neuronal interaction on fluoropolymer surfaces with mixed peptides or spacer group linkers. Biomaterials. 2001; 22(10): 1029-34.

43. Wen X, Tresco PA. Fabrication and characterization of permeable degradable poly (DL-lactide-co-glycolide) (PLGA) hollow fiber phase inversion membranes for use as nerve tract guidance channels. Biomaterials. 2006; 27(20): 3800-9.

44. Verreck G, Chun I, Li Y, Kataria R, Zhang Q, Rosenblatt J, et al. Preparation and physicochemical characterization of biodegradable nerve guides containing the nerve growth agent sabeluzole. Biomaterials. 2005; 26(11): 1307-15.

45. Amado S, Simoes M, da Silva PA, Luís A, Shirosaki Y, Lopes M, et al. Use of hybrid chitosan membranes and N1E-115 cells for promoting nerve regeneration in an axonotmesis rat model. Biomaterials. 2008; 29(33): 


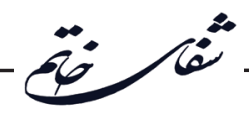

4409-19.

46. Smidsrød O, Skja G. Alginate as immobilization matrix for cells. Trends in Biotechnology. 1990; 8: 71-8.

47. Rhim J-W. Physical and mechanical properties of water resistant sodium alginate films. LWT-Food Science and Technology. 2004; 37(3): 323-30.

48. Amano J, Ito KI, Yamaura K, Matsumoto K, Nakamura T. Fibrosis inhibitor for implanted organ. United States patent; 2011.

49. Sondermeijer HP, Witkowski P, Woodland D, Seki T, Aangenendt FJ, van der Laarse A, et al. Optimization of alginate purification using polyvinylidene difluoride membrane filtration: effects on immunogenicity and biocompatibility of three-dimensional alginate scaffolds. Journal of Biomaterials Applications. 2016; 31(4): 510-20.

50. Klöck G, Pfeffermann A, Ryser C, Gröhn P, Kuttler B, Hahn H-J, et al. Biocompatibility of mannuronic acid-rich alginates. Biomaterials. 1997; 18(10): 707-13

51. Zehnder T, Sarker B, Boccaccini AR, Detsch R. Evaluation of an alginate-gelatine crosslinked hydrogel for bioplotting. Biofabrication. 2015; 7(2): 025001.

52. Orive G, Tam SK, Pedraz JL, Hallé J-P. Biocompatibility of alginate-poly-l-lysine microcapsules for cell therapy. Biomaterials. 2006; 27(20): $\quad 3691-700$.

53. de Groot M, Schuurs TA, van Schilfgaarde R. Causes of limited survival of microencapsulated pancreatic islet grafts. J Surg Res. 2004; 121(1): 141-50.

54. Ashton RS, Banerjee A, Punyani S, Schaffer DV, Kane RS. Scaffolds based on degradable alginate hydrogels and poly (lactide-co-glycolide) microspheres for stem cell culture. Biomaterials. 2007; 28(36): $5518-25$.

55. Purcell EK, Singh A, Kipke DR. Alginate composition effects on a neural stem cell-seeded scaffold. Tissue Eng Part C Methods. 2009; 15(4): 541-50.

56. Khosravizadeh Z, Razavi S, Bahramian H, Kazemi M. The beneficial effect of encapsulated human adiposederived stem cells in alginate hydrogel on neural differentiation. J Biomed Mater Res B Appl Biomater. 2014; 102(4): 749-55.

57. Razavi S, Khosravizadeh Z, Bahramian H, Kazemi M. Time-dependent effect of encapsulating alginate hydrogel on neurogenic potential. Cell J. 2015; 17(2): 304.

58. Hillberg AL, Kathirgamanathan K, Lam JB, Law LY, Garkavenko O, Elliott RB. Improving alginatepoly-L-ornithine-alginate capsule biocompatibility through genipin crosslinking. J Biomed Mater Res B Appl Biomater. 2013; 101(2): 258-68.

59. Günther MI, Weidner N, Müller R, Blesch A. Cellseeded alginate hydrogel scaffolds promote directed linear axonal regeneration in the injured rat spinal cord. Acta Biomater. 2015; 27: 140-50.

60. Kataoka K, Suzuki Y, Kitada M, Hashimoto T, Chou $\mathrm{H}$, Bai $\mathrm{H}$, et al. Alginate enhances elongation of early regenerating axons in spinal cord of young rats. Tissue Eng. 2004; 10(3-4): 493-504.

61. Stucky EC, Schloss RS, Yarmush ML, Shreiber DI. Alginate micro-encapsulation of mesenchymal stromal cells enhances modulation of the neuro-inflammatory response. Cytotherapy. 2015; 17(10): 1353-64

62. Heile AM, Wallrapp C, Klinge PM, Samii A, Kassem M, Silverberg G, et al. Cerebral transplantation of encapsulated mesenchymal stem cells improves cellular pathology after experimental traumatic brain injury. Neurosci Lett. 2009; 463(3): 176-81.

63. Lansdown A, Payne M. An evaluation of the local reaction and biodegradation of calcium sodium alginate (Kaltostat) following subcutaneous implantation in the rat. J R Coll Surg Edinb. 1994; 39(5): 284-8.

64. Smetana K. Cell biology of hydrogels. Biomaterials. 1993; 14(14): 1046-50.

65. Lee DW, Choi WS, Byun MW, Park HJ, Yu Y-M, Lee CM. Effect of $\gamma$-irradiation on degradation of alginate. $\mathrm{J}$ Agric Food Chem. 2003; 51(16): 4819-23

66. Sarker B, Rompf J, Silva R, Lang N, Detsch R, Kaschta J, et al. Alginate-based hydrogels with improved adhesive properties for cell encapsulation. Int J Biol Macromol. 2015; 78: 72-8. 